\title{
Effects of Molding Pressure and Sintering Temperature on Properties of Foamed Glass without Blowing Agent
}

\author{
EunSeok Kim, Kwangbae Kim, Hyeryeong Lee, Ikgyu Kim, and Ohsung Song@† \\ Department of Materials Science and Engineering, University of Seoul, Seoul 02504, Korea \\ (Received January 15, 2019; Revised February 11, 2019; Accepted February 11, 2019)
}

\begin{abstract}
A process of fabricating the foamed glass that has closed pores with $8 \sim 580 \mu \mathrm{m}$ sizes without a blowing agent by sintering 10 $\mu \mathrm{m}$ boron-free glass powder composed of $\mathrm{CaO}, \mathrm{MgO}, \mathrm{SO}_{3}, \mathrm{Al}_{2} \mathrm{O}_{3}-83 \mathrm{wt} \% \mathrm{SiO}_{2}$ at a molding pressure of $0 \sim 120 \mathrm{MPa}$ and a sintering temperature of $750 \sim 1000^{\circ} \mathrm{C}$ was investigated. To analyze the glass transition temperature of glass powder, thermogravimetric analysis-differential thermal analysis (TGA-DTA) method were used. The microstructure and pore size of foamed glass were examined using the optical microscopy and field emission scanning electron microscopy (FE-SEM). For the thermal diffusivity and color of the fabricated samples, a heat flow meter and ultraviolet-visible-near-infrared (UV-VIS-NIR)-colormetry were used, respectively. In the TGA-DTA result, the glass transition temperature of glass powder was confirmed to be $626^{\circ} \mathrm{C}$. In the microstructure result, closed pores of $7 \sim 20 \mu \mathrm{m}$ were formed at $750 \sim 900^{\circ} \mathrm{C}$, and they were not affected by the molding pressure and sintering temperature. However, at $1,000^{\circ} \mathrm{C}$, when there was $0 \mathrm{MPa}$ molding pressure, closed pores of $580 \mu \mathrm{m}$ were confirmed, and the pore size decreased as the molding pressure increased. Moreover, at a molding pressure of $30 \mathrm{MPa}$ or higher, closed pores of approximately $400 \mu \mathrm{m}$ were formed. The porosity showed an increasing trend of smaller molding pressure and larger sintering temperature, and it was controllable in the range of $5.69 \sim 68.45 \%$. In the thermal diffusivity result, there was no change according to the molding pressure, and, by increasing the sintering temperature, up to $0.115 \mathrm{~W} / \mathrm{m} \cdot \mathrm{K}$ could be obtained. The Lab color index (CIE-Lab) results all showed a similar translucent white color regardless of molding pressure and sintering temperature. Therefore, based on the foamed glass without boron and blowing agent, it was confirmed that white foamed glass, which has closed pores of $8 \sim 580 \mu \mathrm{m}$ and a thermal diffusivity characteristic of $0.115 \mathrm{~W} / \mathrm{m} \cdot \mathrm{K}$, can be fabricated by changing the molding pressure and sintering temperature.
\end{abstract}

Key words : Foamed glass, Boron free, Molding pressure, Sintering temperature, Pore size

\section{Introduction}

F oamed glass is also known as "foam glass" and "cellular glass". Uniform pores are formed inside, and thermal insulation and sound absorption characteristics are shown according to the pore shape. ${ }^{1)}$ Foamed glass is monopolized by Pittsburgh Corning, a US company, and based on its manufacturing process, foamed glass is being manufactured. ${ }^{2)}$ In the manufacturing process, seed glass, in which $\mathrm{B}_{2} \mathrm{O}_{3}$ of $10 \mathrm{wt} \%$ or less is added, is fabricated by melting at a high temperature of $1,300 \sim 1,600^{\circ} \mathrm{C}$. Afterward, the fabrication is performed through the following processes: a crushing process that crushes the fabricated seed glass for homogenization; a mixing process that mixes it with a blowing agent; a molding and sintering process that puts a certain amount of pressure in a mold and develops foams by heating; a slow cooling process, in which the foamed glass is slowly cooled because heat transfer is very slow due to ther-

${ }^{\dagger}$ Corresponding author: Ohsung Song

E-mail : songos@uos.ac.kr

Tel : +82-2-6490-2410 Fax : +82-2-6490-2404

ORCID

http://orcid.org/0000-0002-4792-8506 mal insulation; and a shaping process that cuts the foamed glass, which has finished a cooling, into a certain size., ${ }^{2,3}$ The foamed glass fabricated in this method is usually used for thermal insulation of building structures, because it does not combust and produce noxious fumes when fire occurs owing to the insulation characteristic caused by internal pores. ${ }^{4)}$ Particularly, foamed glass with boron is used for the inside of a chimney lining material for flue-gas desulfurization (FGD) of thermal power generation. It is installed inside a chimney and facilitates two protective functions: the chimney support composed of concrete material or steel material under a regular operation temperature of $80^{\circ} \mathrm{C}$ is not deteriorated by heat or corroded by strong acidic gas.

Carta et ll $^{5)}$ have reported that when $10 \%$ or more boron is added to the glass, it interacts with surrounding elements, and the heat stability and bond strength are improved. However, because boron is an additional element that has a relatively high cost, it is a main cause of increase in the manufacturing cost of foamed glass. To solve this problem, Lee et al . ${ }^{6}$ employed $\mathrm{NaCO}_{3}, \mathrm{CaCO}_{3}$, petroleum coke, graphite, etc. as blowing agents to fabricate a foamed glass by using waste glass without boron, and they reported that foamed glass can be manufactured based on the blowing 
agent additive amount. Such foamed glass manufactured without boron has the advantage that it can be produced at a low process cost compared with the conventional foamed glass, but, in the end, there is a problem that a process for adding a blowing agent is required.

Cho et $a .^{7)}$ employed $\mathrm{NaOH}$ as a blowing agent and reported that, in a case of more than $6 \mathrm{wt} \%$ addition, the pore expansion coefficient increased, and the mechanical strength decreased. This means that, when foamed glass is fabricated by adding a blowing agent, the mechanical strength can decrease if the pore size is too large due to the blowing agent over-addition.

Therefore, the purpose of this study was to fabricate foamed glass economically without using boron and, particularly, to investigate whether it is possible to control the closed pores' average size, porosity, and thermal diffusivity characteristics based on the molding pressure and sintering temperature so that the physical properties of foamed glass without boron and blowing agent were confirmed to have the similar properties to those of conventional foamed glass.

\section{Experimental Procedure}

In this study, $2 \mathrm{~mm}$ bulk glass was prepared as a starting material to examine the characteristics of foamed glass fabricated according to the particle size, molding pressure, and sintering temperature. The analysis of composition of samples was conducted by using scanning electron microscopy (SEM)-energy dispersive X-ray spectroscopy (EDS) (JSM6010PLUS/LA, JEOL), and it was confirmed that the prepared glass grits consisted of 82.64 wt $\%-\mathrm{SiO}_{2}, 9.43$ wt\%$\mathrm{CaO}, 4.91 \mathrm{wt} \%-\mathrm{MgO}, 2.18 \mathrm{wt} \%-\mathrm{SO}_{3}$, and $0.84 \mathrm{wt} \%-\mathrm{Al}_{2} \mathrm{O}_{3}$. The bulk glass was dry-crushed by using 10-mm-diameter alumina balls and a planetary mill (Pulverisette 6, FRITSCH), and then, by using a sieve, glass powder composed of particles with $10.7 \mu \mathrm{m}$ average sizes was prepared.

Of the fabricated glass powder, $2 \mathrm{~g}$ was put into a cylindrical metal mold $20 \mathrm{~mm}$ in diameter, and, by using a press (HYDRAULIC Unit Model \#3912, CARVER), uniaxial pressing was performed. Here, using molding pressures of 0,30 , 60,90 , and $120 \mathrm{MPa}$, the shape of a disk green body was produced.

The green body fabricated by changing the molding pressure was sintered at $750^{\circ} \mathrm{C}, 775^{\circ} \mathrm{C}, 800^{\circ} \mathrm{C}, 900^{\circ} \mathrm{C}$, and $1,000^{\circ} \mathrm{C}$, respectively by using a electric furnace (SK1700-B30, Thermo Technology).

As shown in Fig. 1, the sintering process was conducted at a heating rate of $3^{\circ} \mathrm{C} / \mathrm{min}$, and, after the peak temperature was maintained for $5 \mathrm{~min}$, a cooling rate of $1^{\circ} \mathrm{C} / \mathrm{min}$ was applied.

To examine the glass transition temperature of the prepared bulk glass, a thermogravimetric analysis-differential thermal analysis (TGA-DTA) (DTG-60H Dong-il SHIMADZU, Japan) analyzer was used, and, in a nitrogen condition of nitrogen atmosphere (flow rate $30 \mathrm{ml} / \mathrm{min}$ ), the glass transition temperature was examined by measuring with a heat-

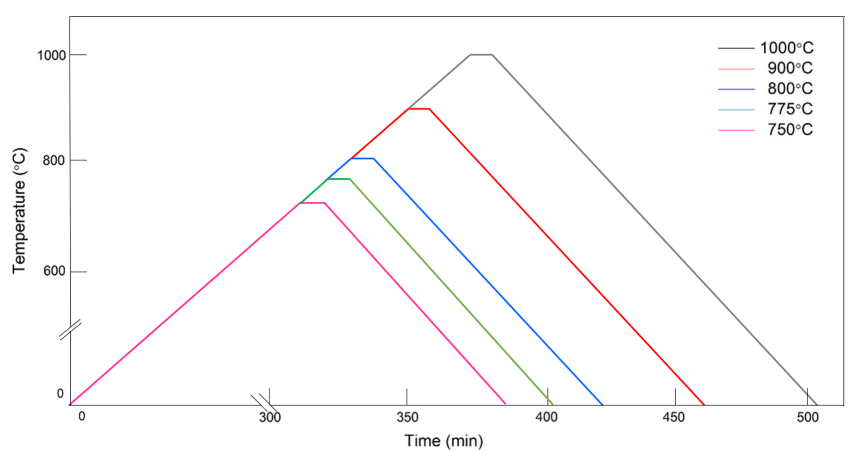

Fig. 1. Sintering process condition of the prepared specimen.

ing rate of $3^{\circ} \mathrm{C} / \mathrm{min}$ in the range of $0 \sim 1,000^{\circ} \mathrm{C}$.

To examine the microstructure of the fabricated foamed glass, an optical microscope (AX-10, ZEISS) and a field emission scanning electron microscope (FE-SEM, S-4300, Hitachi) were used. Using these, the average pore size, porosity and the open pore or closed pore was checked.

The porosity was determined from the area of pore per observation area by using an image analysis program (iSolution DT x64 (IMS digital)) for the analyzed cross-section image. Along with the microstructure, the closed pore was confirmed indirectly by dropping $0.3 \mathrm{ml} \mathrm{H}_{2} \mathrm{O}$ using a spoid on the surface of the foamed-glass. For the component analysis of fabricated foamed glass, an SEM-EDS analysis was performed by crushing the foamed glass with an alumina mortar.

To examine the insulating characteristics, the thermal diffusivity was analyzed by using a heat flow meter (HFM, NETZSCH). Here, in an Ar atmosphere, the measurements were taken three times repetitively with $260 \mathrm{~V}$ and a $600 \mu \mathrm{s}$ pulse width to represent the average value.

For the color of the foamed glass, the CIE-Lab value was examined by using an ultraviolet-visible-near-infrared (UV-VIS-NIR) (UV-3150, SHIMADZU) color meter, and, by measuring in the $300 \sim 800 \mathrm{~nm}$ spectrum, the color difference was analyzed according to the respective molding pressure and sintering temperature based on the Lab index (CIE-Lab) of $0 \mathrm{MPa}-800^{\circ} \mathrm{C}$ foamed glass. ${ }^{8)}$

\section{Results and Discussion}

Figure 2 shows the TGA-DTA result of glass powder. In the TGA result of approximately $182^{\circ} \mathrm{C}$, a small number of weight change was confirmed, and it is thought that this occurred as the moisture of the glass evaporated. The DTA result confirmed an endothermic reaction in the $626 \sim$ $727^{\circ} \mathrm{C}$, and this was determined to be the glass transition temperature. Accordingly, at a temperature of $727^{\circ} \mathrm{C}$ or higher, it was determined that some of the glass powder components can overcome the bonding of the base material and form pores. Therefore, it is determined that pores can be developed at $727^{\circ} \mathrm{C}$ or higher without a blowing agent. ${ }^{2)}$

Table 1 shows the component analysis results of green body and foamed glass fabricated with $1,000^{\circ} \mathrm{C}-5 \mathrm{~min}$. The 


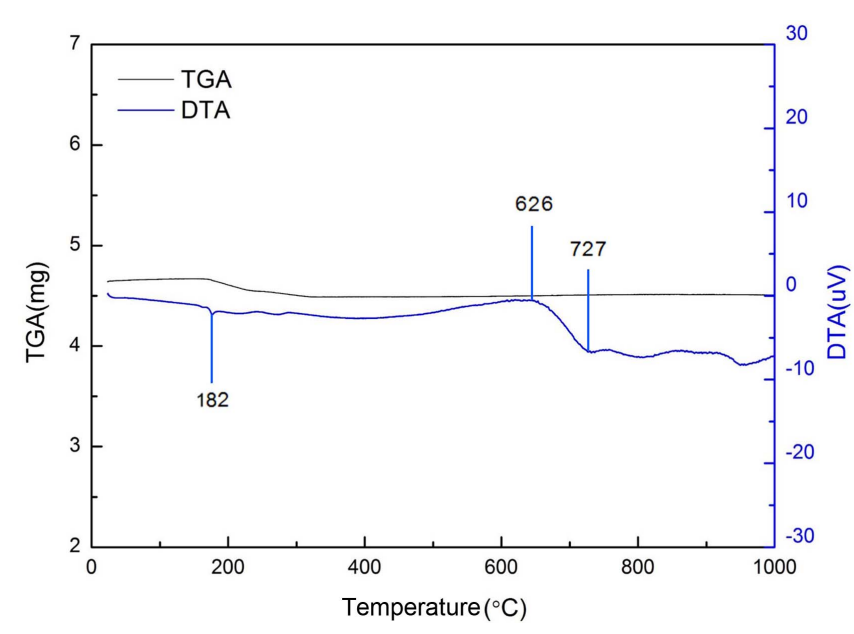

Fig. 2. TGA-DTA data of a glass powder.

Table 1. Properties of Green Body and Foamed Glass.

\begin{tabular}{ccc}
\hline Elements & Green body & Sintered body \\
\hline $\mathrm{SiO}_{2}$ & 82.64 & 83.52 \\
$\mathrm{CaO}$ & 9.43 & 11.74 \\
$\mathrm{MgO}$ & 4.91 & 4.74 \\
$\mathrm{Al}_{2} \mathrm{O}_{3}$ & 0.84 & - \\
$\mathrm{SO}_{3}$ & 2.18 & - \\
\hline Total & 100.00 & 100.00 \\
\hline
\end{tabular}

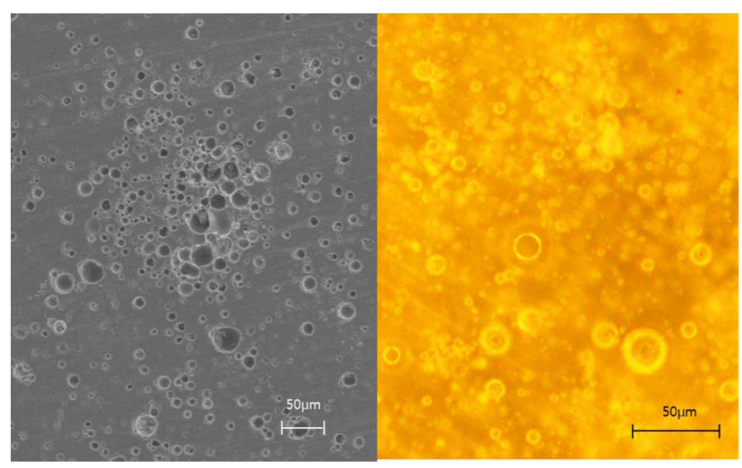

(a)

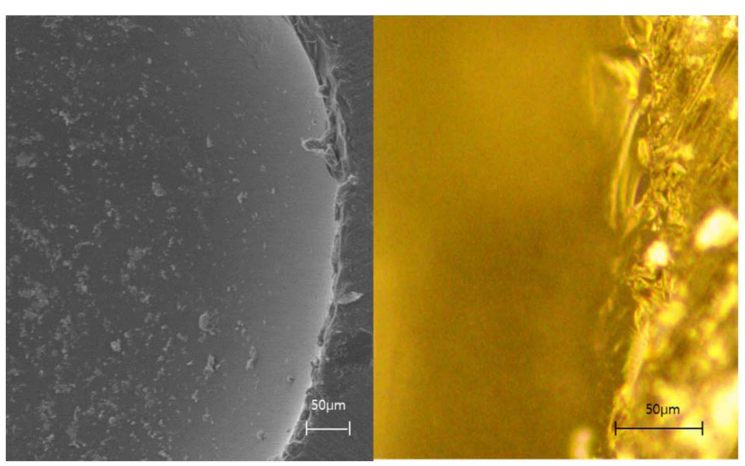

(c) green body's component analysis result confirms that the compositions of $\mathrm{SiO}_{2}, \mathrm{CaO}, \mathrm{MgO}, \mathrm{SO}_{3}$, and $\mathrm{Al}_{2} \mathrm{O}_{3}$ are 82.64 wt\%, $9.43 \mathrm{wt} \%, 4.91 \mathrm{wt} \%, 2.18 \mathrm{wt} \%$, and $0.84 \mathrm{wt} \%$, respectively. Afterwards, however, in the foamed glass's component analysis result, only $\mathrm{SiO}_{2}, \mathrm{CaO}$, and $\mathrm{MgO}$ components were confirmed. Here, a small amount of $\mathrm{Al}_{2} \mathrm{O}_{3}$ existed in the green body, but no trace of it was found in the foamed glass due to the limitation of resolution of EDS. However, in the case of $\mathrm{SO}_{3}$, it is determined to have disappeared due to $\mathrm{SO}_{3} \rightarrow \mathrm{SO}_{2}+1 / 2 \mathrm{O}_{2}$ decomposition reaction. This is consistent with the report of Meng et $\mathrm{al}^{9)}$ for decomposition reaction of $\mathrm{SO}_{3} \rightarrow \mathrm{SO}_{2}+1 / 2 \mathrm{O}_{2}$ at $800 \sim 900^{\circ} \mathrm{C}$ and the report of W. E. Wentworth et al. ${ }^{10)}$ regarding the formation of $\mathrm{SO}_{2}$ and $\mathrm{O}_{2}$ due to reaction of $\mathrm{SO}_{3}$ at $500 \sim 1,000^{\circ} \mathrm{C}$.

Therefore, $\mathrm{SO}_{3}$ was not detected after sintering because, as confirmed in the reports of Meng and Wentworth, it was a reaction result of $\mathrm{SO}_{3}$ at $750^{\circ} \mathrm{C}$ or higher, and it was expected that the pore size would become larger because of volume expansion.

Figure 3 shows the microstructure images of the foamed glasses that were fabricated by sintering the green bodies at $750^{\circ} \mathrm{C}$ and $1,000^{\circ} \mathrm{C}$; the green bodies were fabricated with 0 $\mathrm{MPa}$ and $120 \mathrm{MPa}$ molding pressures, respectively. An image examined with the left-side FE-SEM and an image examined with the right-side optical microscope are shown.

Figure 3(a) shows the microstructure image of the $0 \mathrm{MPa}-$ $750^{\circ} \mathrm{C}$ condition, and, for the pores, it was confirmed that closed pores of a spherical shape were formed. Here, the

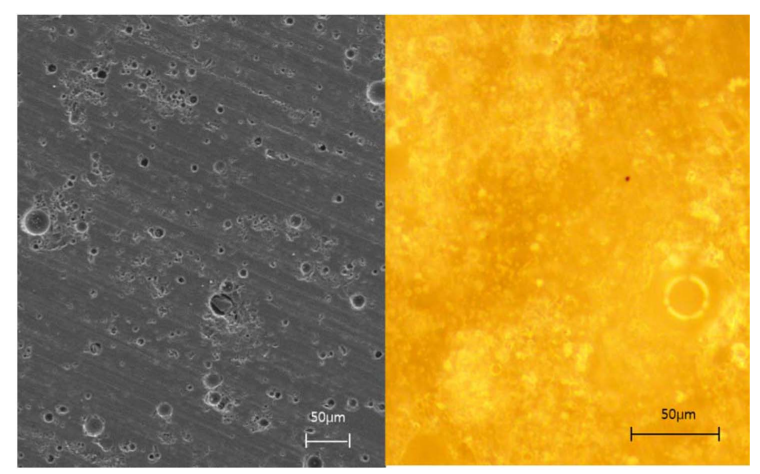

(b)

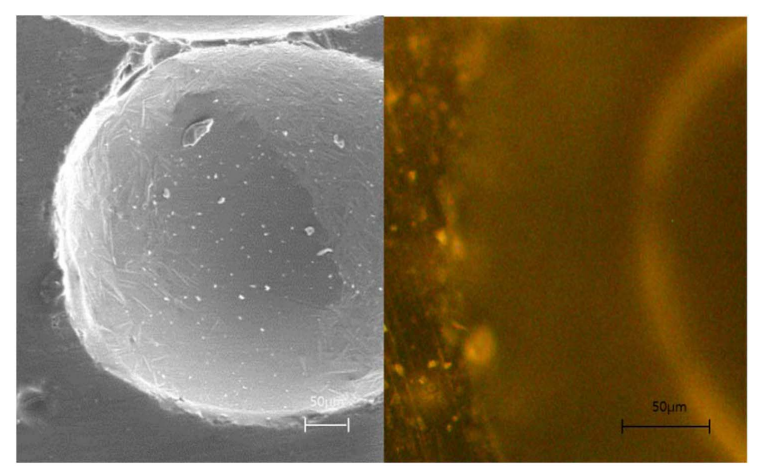

(d)

Fig. 3. Microstructure image (left) and optical microscopy image (right) of sintered material with molding pressure and sintering temperature: (a) $0 \mathrm{MPa}-750^{\circ} \mathrm{C}$, (b) $120 \mathrm{MPa}-750^{\circ} \mathrm{C}$, (c) $0 \mathrm{MPa}-1000^{\circ} \mathrm{C}$, (d) $120 \mathrm{MPa}-1000^{\circ} \mathrm{C}$. 
average pore size was $9.7 \mu \mathrm{m}$. Fig. 3(b) shows the image in the $120 \mathrm{MPa}-750^{\circ} \mathrm{C}$ condition, and closed pores of spherical shape were formed, just like those of Fig. 3(a). Here, the average pore size was $8.0 \mu \mathrm{m}$, which was a similar pore size in the margin of error. It is determined that, at the relatively low $750^{\circ} \mathrm{C}$ sintering temperature, the molding pressure does not affect the pore size.

Figure 3(c) shows the microstructure image in the $0 \mathrm{MPa}-$ $1,000^{\circ} \mathrm{C}$ condition, and it was confirmed that closed pores of spherical shape formed. Here, the average pore size was $578.5 \mu \mathrm{m}$. Fig. $3(\mathrm{~d})$ shows the image in the $120 \mathrm{MPa}-$ $1,000^{\circ} \mathrm{C}$ condition, and, as with Fig. 3(c), spherical closed pores formed. Furthermore, the average pore size was 341.7 $\mu \mathrm{m}$, which decreased by approximately $41 \%$. It was determined that the pore size was smaller because compressive stress, which increasing the viscosity of the porous wall was produced as the molding pressure increased. Therefore, it is determined that the average pore size is affected more by the change in the sintering temperature than the change in the molding pressure.

Figure 4 shows the average pore sizes according to the respective molding pressure and sintering temperature with respect to the results of Fig. 3. Samples fabricated at a sintering temperature of $750 \sim 900^{\circ} \mathrm{C}$ showed the formation of pores with a maximum size of $25.0 \mu \mathrm{m}$. In the temperature range of $750 \sim 900^{\circ} \mathrm{C}$, as the temperature increased regardless of molding pressure, the pore size was $8.0 \sim 23.2$ $\mu \mathrm{m}$, which was proportional to the temperature. In the case of samples fabricated at a $1,000^{\circ} \mathrm{C}$ sintering temperature, when fabricated with $0 \mathrm{MPa}$ molding pressure, pores of about $580.0 \mu \mathrm{m}$ were formed; when fabricated with a 30 $\mathrm{MPa}$ molding pressure, pores of about $400.0 \mu \mathrm{m}$ were formed. Particularly, in the molding pressure range of 60 $120 \mathrm{MPa}$, pores of about $350.0 \mu \mathrm{m}$ average were formed, confirming that the pore size decreased as the molding pressure increased at $1,000^{\circ} \mathrm{C}$ sintering temperature. This confirms that, when the molding pressure is in the $60 \sim 120$ $\mathrm{MPa}$ range, because the densification occurs, the porosity

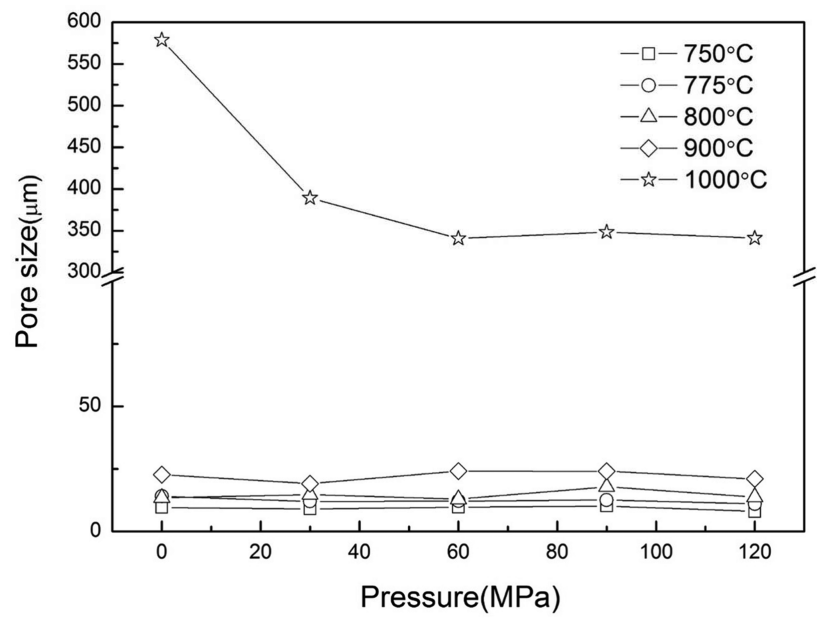

Fig. 4. Pore size of foamed glass with molding pressure and sintering temperature.

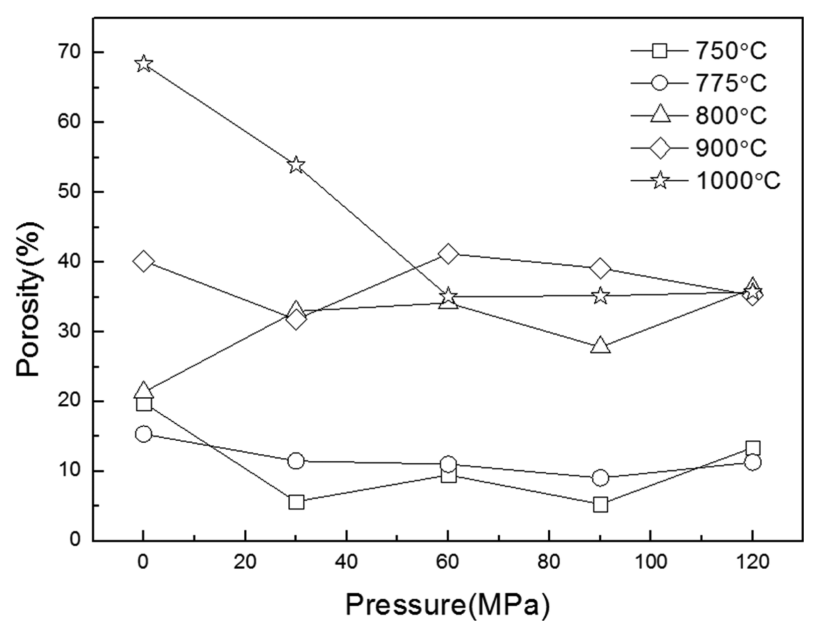

Fig. 5. Porosity of foamed glass with molding pressure and sintering temperature.

decreases by $35 \%$.

In particular, the pore size increased sharply from approximately 340.0 to $580.0 \mu \mathrm{m}$ as the sintering temperature increased to $1,000^{\circ} \mathrm{C}$ because the volume expansion of $\mathrm{SO}_{2}$ and $\mathrm{O}_{2}$ were accelerated as the temperature increased, as described earlier.

In the case of the molding pressure, because of the effect of densification, the size of pores developed from $\mathrm{SO}_{2}$ and $\mathrm{O}_{2}$ were relatively limited due to increase of the viscosity of the porous wall. For example, especially at $1,000^{\circ} \mathrm{C}$, the compressive stress increases as the molding pressure increases. So the viscosity of the glass forming a porous wall may increase. It is determined that the pore becomes small when the molding pressure is relatively high.

Therefore, the results of this study confirm that it is possible to fabricate foamed glass formed with closed pores by controlling the molding pressure and sintering temperature, without boron and a blowing agent. Moreover, it was confirmed that at a sintering temperature of below $900^{\circ} \mathrm{C}$, closed pores with a maximum size of $25.0 \mu \mathrm{m}$ are formed regardless of the molding pressure.

Figure 5 shows the porosity for each condition of fabricated sample. When the molding pressure is constant and the sintering temperature increases, the porosity increases. As described earlier, this is because, as the sintering temperature increases, $\mathrm{SO}_{2}$ and $\mathrm{O}_{2}$ gas produced from $\mathrm{SO}_{3}$ forms large pores through sufficient expansion. In the sintering temperature range of $750 \sim 900^{\circ} \mathrm{C}$, even if the molding pressure increases, there is no significant change in the porosity, as shown in Fig. 4 . However, at a $1,000^{\circ} \mathrm{C}$ sintering temperature, as the molding pressure increases, the porosity decreases, and this is because, as described in Fig. 4, as the molding pressure increases from 0 to $120 \mathrm{MPa}$, the average pore size becomes smaller and the relative pore area decreases as well.

Figure 6 shows the thermal diffusivity analysis result according to the molding pressure and sintering temperature. The thermal diffusivity result shows that the depen- 


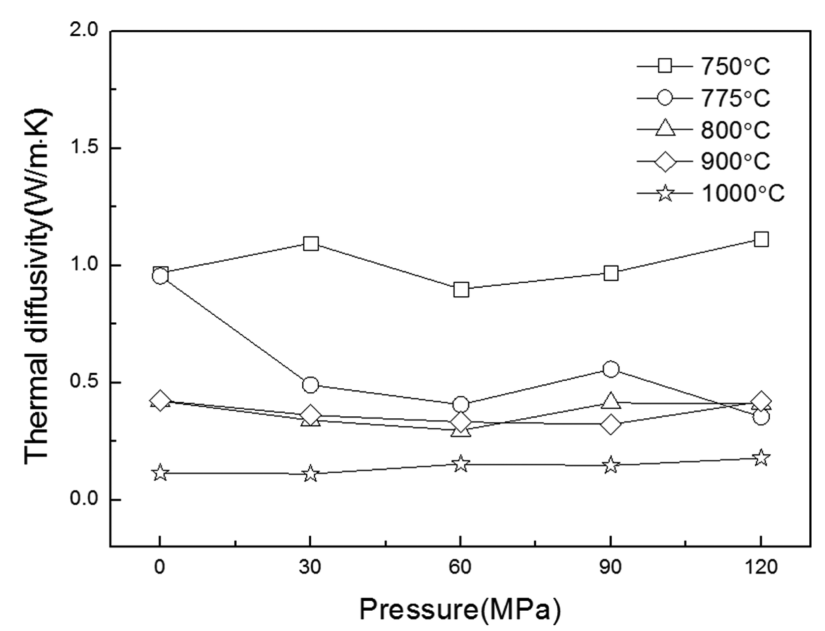

Fig. 6. Thermal diffusivity of sintered material with molding pressure and sintering temperature.

dency on the molding pressure is not large; when the sintering temperature increased, it became lower, and in the $0 \mathrm{MPa}-1,000^{\circ} \mathrm{C}$ condition, a value of $0.115 \mathrm{~W} / \mathrm{m} \cdot \mathrm{K}$ was shown. This result is consistent with the changes in the pore size and porosity confirmed earlier.

The thermal diffusivity of thermal insulation usually used for building structures is approximately $0.035 \sim 0.160 \mathrm{~W} /$ $\mathrm{m} \cdot \mathrm{K},{ }^{11)}$ and the thermal diffusivity of about $0.115 \mathrm{~W} / \mathrm{m} \cdot \mathrm{K}$ confirmed in this study demonstrates potential as thermal insulation. ${ }^{12)}$ Styrofoam, which is widely used conventionally and has excellent thermal conductivity characteristics of $0.036 \mathrm{~W} / \mathrm{m} \cdot \mathrm{K},{ }^{13)}$ but, when fire occurs, it is easily combusted and toxic gas is produced. Therefore, considering the flame resistance characteristics of thermal insulation, the proposed foamed glass can be employed as a safe thermal insulation for building structures.

Table 2 shows the color difference calculated based on the Lab of samples fabricated at $0 \mathrm{MPa}-800^{\circ} \mathrm{C}$ for each condition. Based on the molding pressure and sintering temperature, the color differences of all the samples were 8 or less, confirming that the colors were all similar. This result agrees with the report of Park et al. ${ }^{14)}$ which stated that a color difference of 10 or less is difficult to distinguish clearly with the naked eye. Therefore, it was confirmed that similarly translucent white foamed glasses can be obtained regardless of molding pressure and sintering temperature.

Furthermore, for regular foamed glass, it is known that

Table 2. Comparison of Lab Index of Foamed Glass with Molding Pressure and Sintering Temperature

\begin{tabular}{cccccc}
\hline $\begin{array}{c}\text { Pressure (MPa) } \\
\text { Temperature }\left({ }^{\circ} \mathrm{C}\right)\end{array}$ & 0 & 30 & 60 & 90 & 120 \\
\hline 750 & 1.27 & 1.02 & 1.83 & 3.35 & 4.99 \\
775 & 2.00 & 4.41 & 6.61 & 4.34 & 4.66 \\
800 & 0.00 & 3.63 & 6.50 & 7.95 & 7.63 \\
900 & 4.91 & 6.35 & 6.54 & 6.95 & 7.84 \\
1,000 & 5.21 & 7.48 & 7.56 & 6.99 & 6.44 \\
\hline
\end{tabular}

inorganic compound pigment can be added to materialize a black color, but the result of this study is significant in that the same white color can be materialized regardless of the manufacturing process.

\section{Conclusions}

It was possible to fabricate foamed glass that had the desired pore size, porosity, thermal diffusivity, and color from a boron-free glass grits without a blowing agent. To develop the foamed glass without a blowing agent, it is important to include the $\mathrm{SO}_{3}$ component into the glass material, and the increase in the molding pressure and sintering temperature can become important pore control variables. The average pore size of foamed glass can be controlled in the range of $8.0 \sim 580.0 \mu \mathrm{m}$, and, in all cases, closed pores were confirmed. The porosity can be controlled in the range of $5.69 \sim 68.45 \%$. Furthermore, by adjusting the sintering temperature, the thermal diffusivity can be also controlled in the range of $0.115 \sim 1.113 \mathrm{~W} / \mathrm{m} \cdot \mathrm{K}$. As for the color, translucent white foamed glass can be obtained in all the processes. Therefore, even without boron and a blowing agent, the fabrication conditions of translucent white foamed glass consisting of closed pores were confirmed, whereby the pore size, porosity, and thermal diffusivity can be controlled.

\section{REFERENCES}

1. J. K. Park and J. S. Lee, "Preparation of Porous Inorganic Materials by Foaming Slurry,” J. Korean Ceram. Soc., 35 [12] 1280-85 (1998).

2. C. T. Lee, "The Recycling of Waste Glass - Manufacture of Foamglass and its Prospect," J. Ind. Eng. Chem., 3 [2] 115 (2000).

3. C. T. Lee, "Production Process of Foamed Glass by Compressive Shaping," Appl. Chem. Eng., 24 [3] 239-46 (2013).

4. S. J. Chae, M. G. Park, and W. H. Kang, "Preperation and Properties of Fine Porous Glass," JKAIS, 10 [3] 476-81 (2009).

5. D. Carta, D. Qiu, P. Guerry, I. Ahmed, E. A. A. Neel, J. C. Knowles, M. E. Smith, and R. J. Newport, "The Effect of Composition on the Structure of Sodium Borophosphate Glasses," J. Non-Cryst. Solids, 354 [31] 3671-77 (2008).

6. C. T. Lee, H. G. Lee, and E. H. Um, "Production of Foamed Glass by Using Hydrolysis of Waste Glass - Foaming Process of Hydrated Glass,” J. Ind. Eng. Chem., 16 [6] 760-67 (2005).

7. H. Y. Cho, H. J. Kim, P. K. Chang, C. H. Choi, and S. W. Lee, "A Study on the Physical Characteristics of Foaming Glass by Recycling Waste Glass," J. Korea Acad. Ind. Coop. Soc., 6 [6] 473-77 (2005).

8. Y. W. Kim, J. H. Song, and O. S. Song, "Properties of the Natural and CVD Synthetic Diamonds for Identification," J. Korean Ceram. Soc., 51 [4] 350-56 (2014).

9. L. Meng, M. Kanezashi, and T. Tsuru, "Catalytic Membrane Reactors for $\mathrm{SO}_{3}$ Decomposition in Iodinee Sulfur Thermochemical Cycle: A Simulation Study," Int. J. Hydrogen Energy, 40 [37] 12687-96 (2015). 
10. W. E. Wentworth and E. Chen, "Simple Thermal Decomposition Reactions for Storage of Solar Thermal Energy," Sol. Energy, 18 [3] 205-14 (1976).

11. S. H. Kwon and D. C. Cho, "A Study on Thermal Conduction in Oyster Shell Incorporating Gypsum Objects," Clean Technol., 19 [2] 90-4 (2013).

12. T. S. Yun, Y. J. Jeong, T. S. Han, and K. S. Youm, "Evaluation of Thermal Conductivity for Thermally Insulated
Concretes," Energy and Buildings, 61 125-32 (2013).

13. T. Log, "Transient Hot-Strip (THS) Method for Measuring Thermal Conductivity of Thermally Insulating Materials," Fire Mater., 17 [3] 131-38 (1993).

14. W. H. Park, S. Y. Oh, S. W. Ju, and J. S. Ahn, "Color and Translucency Change by Polymerization of Various Resin Composites," Korean J. Dental Mater., 37 [1] 110-16 (2010). 